\title{
MODOS
}

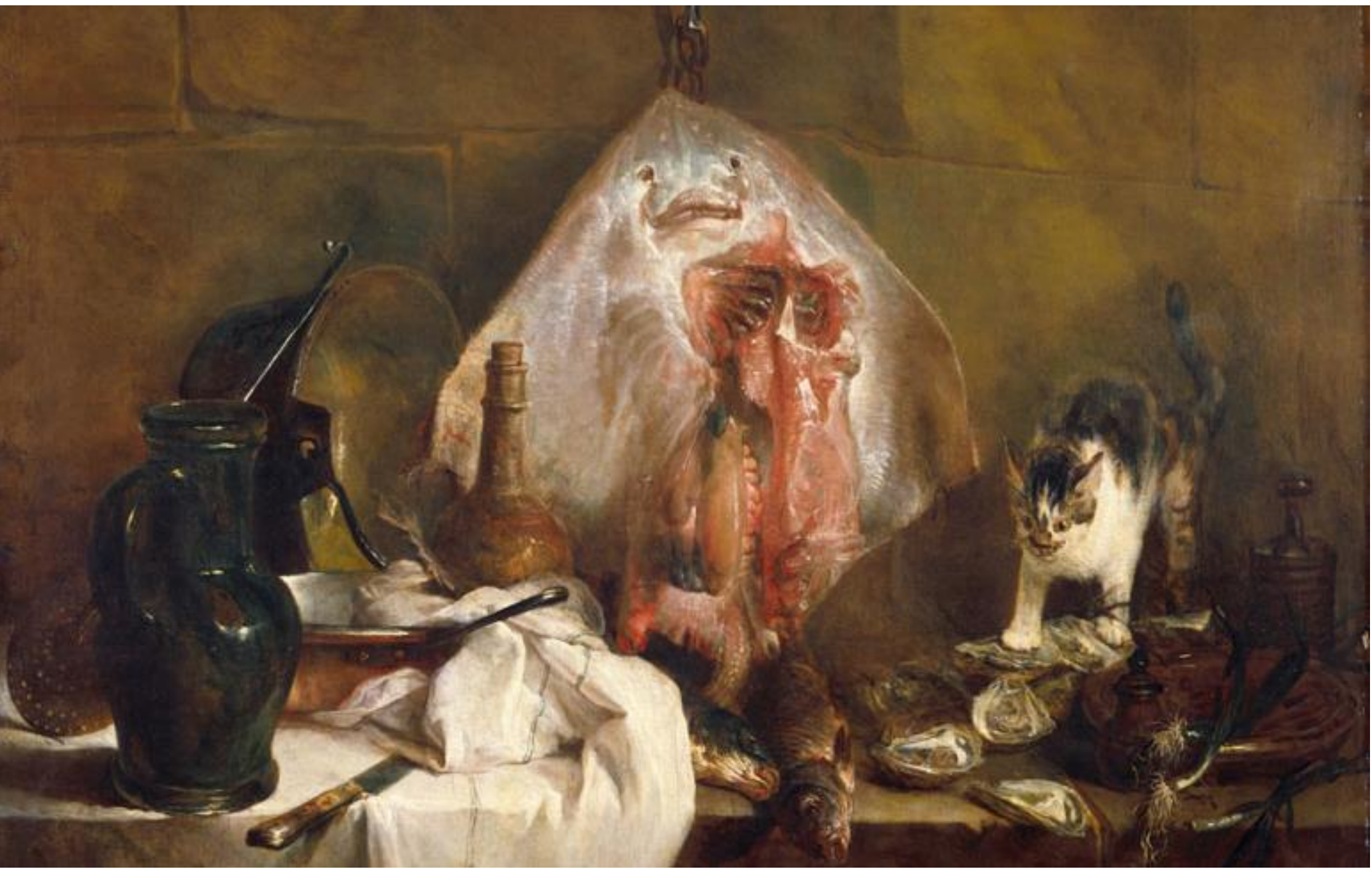

Natureza-morta escrita. Para uma estética do objeto em À la recherche du temps perdu, de Marcel Proust

Written still life. For an aesthethics of the object in Marcel Proust's À la recherche du temps perdu

\section{Dr. Biagio D'Angelo}

Como citar:

D'ANGELO, B. Natureza-morta escrita. Para uma estética do objeto em À la recherche du temps perdu, de Marcel Proust. MODOS. Revista de História da Arte. Campinas, v. 2, n.2, p.214-223, mai. 2018. Disponivel em: <http://www.publionline.iar.unicamp.br/index.php/ mod/article/view/1159>; DOI: https://doi.org/10.24978/mod.v2i2.1159 [detalhe], acervo Museu do Louvre. 


\title{
Natureza-morta escrita. Para uma estética do objeto em $\grave{A}$ la recherche du temps perdu, de Marcel Proust
}

\author{
Written still life. For an aesthethics of the object in Marcel Proust's À la \\ recherche du temps perdu
}

\author{
Dr. Biagio D’Angelo*
}

\section{Resumo}

Este artigo pretende estudar as articulações entre a obra de Proust, Em busca do tempo perdido, e o gênero pictórico da natureza-morta. Para tanto, serão retomadas e problematizadas questões como a complexa relação entre mimesis e ekphrasis; a estética do objeto na representação artística, seja visual ou literária; a estética enciclopédica do "acúmulo", consequência da representação objetual; os limites entre o sujeitoobservador e o objeto-observado; o discurso da memória, ligada ao trabalho poético do acúmulo de objetos, visto como, principalmente, memento mori. A hipótese dessas páginas é a ideia da Recherche ser uma imensa "natureza-morta literária" onde os objetos e sua representação, mesmo na lógica do acúmulo, podem ser considerados como personagens ficcionais, e não meros acessórios, oferecendo assim uma estética do objeto, peculiar na história da cultura textual.

\section{Palabras clave}

Proust; objetos; memória; estética do acúmulo; natureza-morta.

\begin{abstract}
This article intends to study the articulations between the work of Proust, In Search of Lost Time, and the pictorial genre of still life. To do so, questions such as the complex relationship between mimesis and ekphrasis; the aesthetics of the object in artistic representation, whether visual or literary; the encyclopedic aesthetics of "accumulation", as a consequence of object representation; the boundaries between subjectobserver and object-observed; the discourse of memory, linked to the poetic work of the accumulation of objects, seen as, mainly, memento mori, will be retaken and problematized. The hypothesis of these pages is the idea that the Proustian Recherche is an immense "literary still life" where objects and their representation, even in the logic of accumulation, can be considered as fictional characters, not as mere accessories, offering, thus, an aesthetic of the object, very peculiar in the history of textual culture.
\end{abstract}

\section{Keywords}

Proust; Objects; Memory ; Aesthetics of "accumulation"; Still life. 
Ese cuadro es un texto, es un enigma y, como todos los enigmas, no es algo que se contempla sino que se descifra.

(Octavio Paz, Apariencia desnuda)

L'allégorie de la vérité en peinture est loin de s'offrir toute nue sur un tableau.

(Jacques Derrida, La vérité en peinture)

"O que resta para escrever depois de Proust?", escrevia Virgínia Woolf a Roger Fry, numa carta de 1922. A pergunta de Virgínia Woolf, mesmo se inibidora, é ainda o que move o crítico da literatura e da história da arte a escrever depois de Proust.

Na obra-mestra de Marcel Proust, Em busca do tempo perdido (À la recherche du temps perdu), 19131927), o papel da memória é central. Da lembrança suscitada pela célebre cena da madeleine à narração da morte da avó do narrador, cuja agonia é retratada como um lento desfazer de um sujeito, a memória imbui a obra proustiana, até em seus campos literários metarreferenciais: as Cartas, de Madame de Sévigné, leituras preferidas pela avó e pela mãe do Narrador, por exemplo, representam quase uma analogia com as memórias narradas. À memória é dedicada uma atenção peculiar no último volume do romance, O Tempo Reencontrado, em que o autor utiliza um procedimento analéptico, fazendo com que ele recue no tempo das suas memórias, em episódios desencadeados por recordações de cheiros, sons, paisagens ou mesmo sensações tácteis.

Também se sabe que uma grande parte do romance se debruça sobre a natureza da arte. Proust promove uma visão da arte muito moderna, que parece antecipar certa tendência conceitual da estética contemporânea. Se todos somos artistas potenciais, como também quis afirmar e promulgar Andy Warhol, é porque a arte é a capacidade de transformação das experiências de vida quotidiana em algo que possa ser revelador de uma realidade outra. As artes visuais são abordadas abundantemente. Kazuyoshi Yoshikawa que, em Proust et l'art pictural (2010), investigou, particularmente, a importância dos quadros de Rembrandt na obra proustiana, evidencia no escritor francês quase um museu imaginário1. 0 crítico japonês se ocupa não apenas dos quadros que o Narrador explicitamente menciona, mas também daquelas outras visualidades que estariam ocultadas na Recherche com alusões que assumem, ao longo da obra, uma grande relevância teórica e filosófica.

O pintor Elstir, um dos personagens mais emblemáticos da Recherche, representa, neste sentido, uma síntese da arte moderna e da tipologia ideal de artista. Elstir, que aparece pela primeira vez na parte intitulada Un amour de Swann, metaforiza o interesse proustiano para com a pintura. Além disso, Elstir representa, para o Narrador, não apenas um pintor contemporâneo, mas a pintura contemporânea, convencido do fato de que exista uma evolução contínua na história da arte e da cultura tout court.

A relação entre Proust e as artes plásticas tem sido amplamente estudada. Recentemente, o volume Proust and the Arts, uma coletânea de artigos, editada por Christie McDonalds e François Proulx pela 
Cambridge University Press (2015), fez o ponto da situação atual dos estudos sobre o lugar das artes na escrita proustiana.

Todavia, nossa intuição vai além de uma mera comparação entre as artes visuais e a proposta proustiana. Ao nosso ver, seria possível considerar a Recherche proustiana como uma tentativa de transposição semiótica do gênero pictórico da natureza-morta nos moldes de uma prática literária, de uma prática da escrita. Com efeito, a Recherche proustiana é legível como uma enciclopédia pluridiscursiva e plurilíngue aberta, em que os objetos, assim como as personagens, representam uma autêntica still life, isto é uma "ainda vida", uma vida da memória, ou como propôs Giorgio de Chirico, aquela vida silenciosa da memória, que é a natureza-morta ${ }^{2}$. Conjeturar que a Recherche seja "lida" e "vista" como uma imensa natureza-morta explicaria não apenas a construção de uma "catedral" textovisual unitária, com um sentido e um significado filosófico claro, mas constituiria a retomada da tradição tipicamente francesa da Encyclopédie, em que os objetos, presentes, organizados, classificados e sintetizados, vivem e morrem, tal como seres vivos. Por sua estrutura, a obra proustiana torna-se, assim, um arquitexto (objetos, vanitas, memento mori, contemplação, tempo, memória) de obras que se apropriam de e citam a natureza-morta como gênero e escolha discursiva visual. Na obra proustiana 0 discurso das artes visuais, que se incarna e se revela, especificamente, no artista ficcional Elstir, é percebido, pelo autor, como possibilidade contemplativa da realidade, tanto no sentido do desejo utópico-enciclopédico da experiência subjetiva, quanto em sua significação de permanência ficcionalizada. Nesse sentido, fundamental é a leitura crítica da obra visual de Jean-Baptiste Chardin, 0 pintor das naturezas-mortas e dos objetos domésticos, ao qual também a fortuna crítica proustiana contribuiu enormemente. A produção estética de Chardin, segundo Proust - ou deveríamos dizer, graças a ele - assumiria, logo depois, uma modernidade assustadora.

Proust escreveu umas páginas magníficas sobre Chardin. Para Yoshikawa, as naturezas-mortas de Chardin foram a grande oportunidade de ver refletido na pintura essa busca incessante e alarmante dos detalhes mais banais do cotidiano a serem memorizados para sempre. Chardin, portanto, seria um dos fundamentos visuais de uma poética aguçada do olhar ou seriam, como Yoshikawa escreve, "as bases da estética que deveria perpassar toda a Recherche"3 (Yoshikawa, 2010: 360).

A estética do objeto é exaltada na observação crítica de Proust e aparece como a poética do fazer chardiniano de pintura:

A natureza-morta é, acima de tudo, uma mudança de uma vida em ação. Como a própria vida, ele sempre terá algo a dizer para você, algumas maravilhas brilhando, algum mistério para revelar. Dia-a-dia a vida irá deliciar você durante vários dias se prestar atenção à sua pintura como se fosse uma lição; e tendo compreendido a vida de suas pinturas, ter-se-á alcançado a beleza da própria vida. Em salas onde não se vê nada, a não ser a expressão da banalidade dos outros, o reflexo de seu próprio tédio, Chardin entra como luz, dando a cada objeto sua cor, evocando a partir da noite eterna que envolve os objetos toda a essência da vida, viva ou animada, com o significado de sua forma, tão marcante para os olhos, e tão obscuro para a mente. Como a princesa adormecida desperta, tudo é restaurado à vida, retoma a sua cor, começa a falar com você, vivo, duradouro (Proust, 1994: 103, grifo nosso) 4 . 
A natureza-morta, essa quintessência dos objetos e dos detalhes, seria a possibilidade de ver a vida ainda em ação. Os objetos, silêncios, inertes, aí representados, podem proporcionar ao observador a revelação tênue, discreta de algum mistério. Há uma lição "oriental", poderíamos dizer, na contemplação dos objetos, pois eles nos revelam a beleza da vida, sua essência, e a luz e a sombra detectam as dobras imperceptíveis dos tecidos (dos textos) das coisas.

Este frenesi detalhista poderia deixar a impressão de que Proust continue, historicamente, a acreditar numa arte realista. Trata-se de uma questão complexa, secular, desde Aristóteles. Ou a arte é entendida como imitação do real e, portanto, deverá incumbir-se da responsabilidade de "corrigi-lo", talvez "deformá-lo", ou, pelo contrário, ela se reconfiguraria como uma cópia fiel do real. Contudo, em ambos casos, estamos frente a uma declaração de utopia, isto é, frente à impossibilidade de "dizer" o real. Narrar o real seria outro assunto. Então, tratar-se-ia de reinventar certos dados com um acréscimo agravante: o real possuiria algo, um elemento, um quid, que não pode ser capturado. Quem sabe, a grande realização do fato artístico consista justamente nisso: capturar o "incapturável". Talvez, essa constatação está presente numa afirmação do Narrador na última fase da Recherche, Le Temps retrouvé :

De forma que a literatura que se contenta com "descrever as coisas", com oferecer um registro infeliz de linhas e superfícies, é aquela que, ao chamar-se realista, é a mais distante da realidade, aquela que nos empobrece e nos entristece mais, porque corta de repente toda a comunicação do nosso eu presente com o passado, do qual as coisas mantêm ainda a essência, e com o futuro, onde elas nos encorajam a apreciá-las novamente. É isso que a arte digna desse nome deveria expressar, e, se conseguir, ela ainda pode obter de sua impotência um ensinamento (enquanto não se obtenham outros resultados desse tal realismo), e isto é, que essa essência é em parte subjetiva e incomunicável (Proust, 1989: 191-192, grifo nosso) ${ }^{5}$.

François Soulages (2018: 11)6 escreve que o pintor experiente é consciente que o realismo não é possível. Ele é uma utopia. Assim mesmo poder-se-ia dizer do escritor. 0 que eles têm à disposição (pincel e pluma, dir-se-ia do ponto de vista clássico, tradicional) é um meio com que eles conseguem ler e ver o real. Essa leitura, essa visão é o material próprio a eles. Neste sentido, é interessante observar essa materialização da visão por meio da leitura alegórica de objetos operada pelo poeta e ensaísta polonês Zbigniew Herbert (1924-1998). Herbert publica, em 1993, um ensaio intitulado Martwa natura $z$ wędzidłem (Natureza-morta com rédea), dedicado ao pintor holandês do século XVIII Torrentius. Desse pintor, que foi perseguido por ser amante das ciências ocultas, ficou somente uma obra, justamente a Natureza-morta com rédea. Essa pintura parece contradizer toda a biografia do pintor. Herbert fica fascinado, curioso pelo fato de que os objetos daquela natureza-morta que representam ordem, temperança, prudência, seriam as virtudes opostas às caraterísticas existenciais do pintor rebelde. Herbert não se convence com a alegoria da Moderação. Identifica até uns erros de holandês e conclui dizendo que se trata de uma deliberada violação da ordem, e, portanto, que a natureza-morta mostra o que ficou sensivelmente escondido. Os objetos representados não são, sempre, necessariamente aquilo que se propõem a aparentar. Em vez disso, a questão é como os objetos são observados, como Herbert mesmo declara num breve poema em prosa, Objects: 
Os objetos inanimados são sempre corretos e não podem, infelizmente, ser culpados de nada. Nunca observei que uma cadeira possa mudar de um pé para outro, ou uma cama possa se levantar sobre suas patas traseiras. E as mesas, mesmo quando estão cansadas, não se atrevem a dobrar seus joelhos. Suspeito que os objetos façam isso a partir de considerações pedagógicas, para nos repreender constantemente da nossa instabilidade (Herbert, 1968: 63)

Herbert alerta sobre essa vida oculta dos objetos. Com efeito, ao falarmos de estética do objeto, fazemos referência não tanto e não apenas às suas características ligadas ao conhecimento do belo natural e artístico, ou do juízo moral e espiritual, mas às suas estratégias hermenêuticas que, unidas ao juízo, oferecem do objeto sua simbolização aberta, constantemente re-interpretável.

$\mathrm{Na}$ Recherche o discurso estético do objeto transita entre uma peculiar poética visual, ligada especialmente ao gênero pictórico da natureza-morta, de que a escrita proustiana se encarrega de fazer uma transposição singular, e o sujeito observador, aquele Narrador que precisa do objeto para que seu monumento à Memória possa funcionar como enciclopédia do "acúmulo", consequência da representação (mimesis e ekphrasis) objetual. Já na Recherche, o Narrador adverte: "(...) Eu não tinha experimentado, ao tentar essa descrição, nada do entusiasmo que não é o único, mas que é o primeiro critério do talento"s. O primeiro critério do talento é descrever. É a grande questão que angustia Bergotte, quando frente à Vista de Delft de Vermeer, percebe em si uma sensação de incompletude, de finitude, dada pela diferença entre 0 dado (o quadro, a arte) e a própria experiência poética singular, mas limitada:

Enfim chegou diante de Vermeer, de que se lembrava como sendo mais luminoso, mais diferente de tudo que conhecia, mas onde, graças ao artigo de crítico, reparou pela primeira vez numas figurinhas vestidas de azul, na tonalidade cor de rosa da areia e finalmente na preciosa matéria do pequenino pano de muro amarelo. As tonteiras aumentavam; não fixava os olhos, como faz o menino com a borboleta amarela que quer pegar, do precioso panozinho de muro. "Assim é que eu deveria ter escrito", dizia consigo. "Meus últimos livros são demasiado secos, teria sido preciso passar várias camadas de tinta, tornar a minha frase mais preciosa em si mesma, como este panozinho de muro" (Proust, 2011: 212).

Assim que Bergotte deveria ter escrito: modalizando o objeto mais irrisório ou aparentemente sem valor algum, dando espaço à escrita para que o objeto penetre outro espaço mais vasto, enciclopédico e interrogue o observador sobre a relação enigmática do objeto com o sujeito:

A descrição está sempre lidando com um horizonte de expectativa pré-estabelecido, portanto, com um padrão, um código, um modelo pré-existente. Modalizar uma descrição significa questionar o grau de integridade e legitimidade do modelo, da taxonomia (de palavras, de coisas), desenvolvido em outra área do conhecimento (enciclopédia, dicionário, ciência e tecnologia), isto é questionar a competência do conhecimento em geral (Hamon, 1993: 121)9.

A descrição em Proust é uma estratégia de necessidade ontológica da escrita. Ela "vitimiza" o Narrador e o escritor, sacrificando-o no altar do árduo trabalho artístico. Descrever um objeto produz um efeito 
catalizador no Narrador, pois ele se ilude de poder possuir as coisas do mundo, sua fisicidade, assim como seu sentido transcendente. A própria corporalidade do Narrador assume uma independência soberana, justamente na gestualidade de descrever e/ou contemplar objetos e detalhes. $\mathrm{Na}$ obra de Proust, os objetos representam um mundo precário e problemático. É verdade que a Memória possibilita uma espécie de junção utópica entre o eu e o real, mas o sujeito precisa da obra de arte para fixar 0 objeto e determinar seus aspectos mais contraditórios e mais verdadeiros.

Desta forma, descrever um objeto torna-se, como diria Barthes, mas não a propósito de Proust, uma "tagarelice", isto é, uma "espuma de linguagem que se forma sob o efeito de uma simples necessidade da escritura" (Barthes, 2008: 9). Todo o projeto proustiano de assoberbar o texto de detalhes, notícias, fofocas, debates, conversas, alia-se a um conjunto de cores, sabores, lembranças, descrições minuciosas que parecem fazer implodir o texto para uma estrutura enciclopédica em que cada objeto morto se revitaliza pela arte. A Recherche pode ser lida, então, tanto como um gigantesco afresco pictórico, mas também como uma imensa natureza-morta. Literatura e arte se encontram num diálogo intersemiótico que se totaliza tanto no efeito literário quanto no processo meramente visual. Se a poética proustiana é uma "estética do ínfimo, do minúsculo" (Leandro, 2015: 65), ela é também uma estética macroscópica, que promove a visão perspectivista tanto pela lupa, quanto pela lente de encolhimento. Proust é um novo Galileu, cujo telescópio enxerga o objeto como metáfora da geografia humana, social e política. Trata-se de uma estética pontual, arquitetada nas mínimas nuanças, uma estética que pretende manipular uma weltanschauung, isto é, uma tentativa de ordem filosófica do cosmos, como justamente propõe Sophie Bertho: "Proust se interessa (...) somente àquelas pinturas que se integram em sua estética, que são susceptíveis de transformar nossa visão da realidade" (Bertho, 1996: 94) ${ }^{10}$.Todavia, a abundância de citações artísticas, a estratégia discursiva ecfrástica, a atenção milimétrica de registrar o mínimo acontecer presenciado não deve fazer pensar em uma proposta enciclopédica estéril e vazia. A enciclopédia proustiana faz parte de um projeto filosófico que permite que os seres animados e inanimados assumam um espaço significativo na ordem-desordem do mundo. Trata-se não tanto de um acúmulo documental ou arquivístico, mas de uma perspectiva de fixar as coisas numa perenidade acumulativa, num amontoamento "econômico", familiar e, ao mesmo tempo, sistemático que serve a dar sentido à existência. Tudo interessa ao Narrador (e ao Escritor) para que a arquitetura funcional da memória e a memória íntima, subjetiva, sejam investidas da luz chiaroscural do projeto da "busca". Nessa procura de enaltecer o dado inanimado, há algo de oriental em Proust, o que despertou a atenção crítica do francesista japonês Kazuyoshi Yoshikawa, e que Luc Fraisse tem evidenciado a propósito de uma tendência ao japonismo em Proust, uma presença consistente nas páginas da Recherche "porque ele oferece, primeiramente ao herói, mas principalmente ao narrador, objetos que servirão como elementos condutores até a memória" (Fraisse, 1990: 38)11.

Se a essência da obra de arte é incomunicável, então a literatura - gigantesco criptotexto - oculta, atrás de descrições, acúmulos, visões, imagens e sensações, o realismo e liberta, pela imaginação finalmente despertada, o real. Por real, Proust não entende, obviamente, o exclusivo limite da tangibilidade das coisas. A pintura, por exemplo, realiza, por meio de sinestesias, alusões misteriosas, recordações, 
aquelas conexões sugestivas entre o material e o metafísico. Mesmo que possa parecer tautológico, a estética do objeto esconde outro questionamento: o fato de os objetos serem um problema estético, filosófico. Para necessidade de investigação, o artista deverá catalogá-los. Eles estão diante dele como um relicário, coisas mortas com valor de vivas, naturezas que aspiram à contemplação do Tudo, relembrando a vaidade do tudo. Catalogar e classificar os objetos é, por exemplo, a atitude ansiosa de Proust e de seu Narrador. Francesco Orlando, que o comparatista Piero Boitani denomina o "Lineu" da crítica literária italiana, em sua operação classificatória dos objetos desatualizados na literatura e nas artes, propõe que a taxonomia dos objetos seja considerada como a "busca de palavras exatas por aproximação":

\begin{abstract}
O espaço da operação classificatória será aquele que existe entre um puro dado de matéria do conteúdo - algo como um mínimo comum denominador semântico - e a série de textos para que esse dado, de fato, é comum. Vamos imaginar o assunto abstrato como um ponto quase imaterial, no topo; a seguir, a literatura concreta, como uma linha reta composta de vários segmentos, cada um dos quais corresponde ao sintagma linear de um texto. No meio, o espaço vazio corresponde a uma falta de vocabulário bem definido para as nossas constantes - melhor definidas daquelas usadas até agora -, considerando que a classificação não é nada mais do que a busca por apenas palavras de aproximação (Orlando, 2015: 71, grifo nosso) ${ }^{12}$.
\end{abstract}

Não se trata, em outras palavras, de tentativas que o escritor e pintor possuem como estratégias discursivas para a descrição, a ekphrasis? Certo, como escreve Michele Cometa, "a literatura produz constantemente falsos pictóricos" (2010: 189), também essa classificação se baseia numa falsidade "por aproximação". Descrever o objeto é classifica-lo, catalogá-lo para que entre num museu imaginário que incansavelmente o regenere. É o que, intuímos, desejou Proust com o projeto da Recherche. Todavia, para que esse projeto chegue às suas mais profundas consequências, isto é, à sua realização profética de que a Arte é a única forma falsa de dizer o verdadeiro, será necessário reconhecer: encontrar o dado (encontrar o objeto) é sacrificar-se a si mesmo. Proust o sabia bem. Ao longo de toda a Recherche o Narrador descreve, vê e se sacrifica. Entre o objeto e o observador existe, assim, uma "lacuna", uma "fratura", que necessita da colaboração hermenêutica do observador para que ela se transforme em arte e descreva finalmente 0 (in)visível.

\title{
Referências
}

BARTHES, Roland. O prazer do texto. São Paulo: Perspectiva, 2008.

BERGSTRÖM, Ingvar. Historical introduction. In: Dutch still life painting in the seventeenth century. 2 ed. Translated by Christina Hedström. New York: Hacker Art Books, 1983, p. 1-41.

BERTHO, Sophie. Ruskin contre Sainte-Beuve: le tableau dans l'esthétique proustienne. Littérature, Paris, n. 103, p. 94-112, 1996.
COMETA, Michele. Un'antropologia del falso: letteratura e pittura. In: SCALABRONI, L. (ed.). Falso e falsi. Prospettive teoriche e proposte di analisi. Pisa: ETS, 2010, p. 189-208.

FRAISSE, Luc. L'CEuvre cathédrale. Proust et l'architecture medievale. Paris: Corti, 1990.

GROOTENBOER, Hanneke. The paradox of still life. Oxford Art Journal, Oxford, vol. 34, issue 3, p. 486-488, 2011.

HAMON, Philippe. Du descriptif. Paris: Hachette, 1993. 
HERBERT, Zbigniew. Selected Poems. Harmondsworth: Penguin Books, 1968.

LEANDRO VILELA, João Gonçalves. A poética do detalhe no episódio da lanterna mágica em $A$ la recherche du temps perdu. 2015. Tese (Doutorado em Estudos Lingüísticos, Literários e Tradutológicos em Francês) - Faculdade de Filosofia, Letras e Ciências Humanas, Universidade de São Paulo, São Paulo.

MCDONALDS, Christie; PROULX, François. Proust and the arts. Cambridge: Cambridge University Press. 2015.

ORLANDO, Francesco. Gli oggetti desueti nelle immagini della letteratura. Torino: Einaudi, 2015.

PROUST, Marcel. À la recherche du temps perdu. Paris: Édition en 7 volumes Direction de J.-Y. Tadié, 1988-1990.

Alla ricerca del tempo perduto, a cura di Luciano De Maria, edizione annotata da Alberto Beretta Anguissola e Daria Galateria, traduzione di Giovanni Raboni, "Oscar" in 8 volumi, Milano: Mondadori, 1983 e 1989-2001.

Chardin: The essence of things. In: Against Sainte-Beuve and other essays. Transl.by John Sturrock. London: Penguin Books, 1994, p.101-106.
Em busca do tempo perdido. Traduções por Mário Quintana (vols. 1 a 4) Manuel Bandeira e Lourdes Sousa Alencar (vol. 5), Carlos Drummond de Andrade (vol. 6) e Lúcia Miguel Pereira (vol. 7). São Paulo: Globo, 2010-2012.

YOSHIKAWA, Kazuyoshi. Proust et l'art pictural. Paris: Honoré Champion, 2010.

Proust et Rembrandt, In: BRUN,

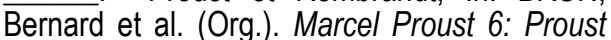
sans frontières. Caen: Lettres Modernes Minard, 2007, p. 105-120.

SOULAGES, Francois. Les archives des temps effacés. In: D'ANGELO, Biagio; SOULAGES, François (eds). Temps. Photographie \& littérature. Ecrits parisiens 2017-2018, 2. Paris: L'Harmattan, 2018.

STERLING Charles. La nature morte de l'antiquité à nos jours. Paris: Éditions Pierre Tisné, 1952.

STOICHITA, Victor. The Surprised Eye. In: The self-aware image: an Insight into early modern meta-painting. Translated by Anne-Marie Glasheen. Cambridge: University Press, 1997, p. 3-63.

\title{
Notas
}

\begin{abstract}
* J Biagio D'Angelo é professor do curso de Teoria, História e Crítica da Arte na Universidade de Brasília e pesquisador do CNPq (PQ2). Este texto foi escrito durante um profícuo período de estudo e pesquisa na Universidade de Paris VIII Saint-Denis, graças a um auxílio de bolsa de pós-doutorado no exterior (agosto 2017- julho 2018) outorgado pelo CNPq. E-mail: biagiodangelo@gmail.com.

10 crítico japonês não se ocupa apenas de Rembrandt, nesse ensaio, mas também de Vermeer, El Greco e outros pintores. Um artigo mais específico, sobre as relações intersemióticas entre Proust e Rembrandt é "Proust et Rembrandt" (Yoshikawa, 2007: 105-120).

2 Apesar do gênero da natureza-morta ser um dos pilares da tradição iconográfica da história da pintura ocidental, estamos conscientes de uma escassa repercussão bibliográfica em língua portuguesa no Brasil, a respeito. Parece-nos necessário lembrar aqui alguns estudos clássicos, ainda de certa importância histórico-metodológica, como Charles Sterling (1952) e Ingvar Bergström (1983: 1-41), e, entre outras manifestações mais recentes, os textos de Hanneke Grootenboer (2011: 486-488) e Vitor Stoichita (1997: 3-63).

3 "Les bases de l'esthétique qui devait par la suite traverser l'ensemble de la Recherche". A tradução é nossa.

4 "Still-life will, above all, change into life in action. Like life itself, it will always have something to say to you, some shining marvel, some mystery to reveal. Day-to-day life will delight you if for several days you pay attention to his painting as though it were a lesson: and having understood the life of his painting you will have conquered the beauty of life itself. In rooms where you see nothing but the expression of the banality of others, the reflection of your own boredom, Chardin enters like light, giving to each object its color, evoking from the eternal night that shrouded them all the essence of life, still or animated, with the meaning of its form, so striking to the eye, so obscure to the mind. Like the sleeping princess awakened, everything is restored to life, resumes its color, starts speaking to you, living, enduring". Tradução nossa.

5 "De sorte que la littérature qui se contente de 'décrire les choses', d'en donner seulement un misérable relevé de lignes et de surfaces, est celle qui, tout en s'appelant réalistes, est la plus éloignée de la réalité, celle qui nous appauvrit et nous attriste le plus, car elle coupe brusquement toute communication de notre moi présent avec le passé, dont les choses gardaient l'essence, et l'avenir où elles nous incitent à la goûter de nouveau. C'est elle que l'art digne de ce nom doit exprimer, et, s'il y échoue, on peut encore tirer de son
\end{abstract}


impuissance un enseignement (tandis qu'on n'en tire aucun de ses réussites du réalisme), à savoir que cette essence est en partie subjective et incommunicable". Tradução nossa.

60 texto completo é o seguinte: "Le vieux peintre a compris que le réalisme n'est même pas possible. II pose sur sa toile des touches de peinture et les relie par d'autres. II fait de la peinture. C'est pour cela qu'on l'appelle peintre. Le vieil écrivain ne fait que la même chose. II pose sur sa feuille des mots et les relie par d'autres. II fait de l'écriture. C'est pour cela qu'on l'appelle écrivain. Ce n'est pas un doctrinaire, un réaliste, un théoricien, un idéologue. Eux savent à l'avance ce qu'ils veulent faire. Puis ils écrivent et peignent. Leur médium n'est qu'un moyen. Leur matériau aussi" (Soulages, 2018: 11).

7 "Inanimate objects are always correct and cannot, unfortunately, be reproached with anything. I have never observed a chair shift from one foot to another, or a bed rear on its hind legs. And tables, even when they are tired, will not dare to bend their knees. I suspect that objects do this from pedagogical considerations, to reprove us constantly for our instability". Tradução nossa.

8 "Je n'avais éprouvé en essayant cette description rien de cet enthousiasme qui n'est pas le seul mais qui est un premier critérium du talent". Tradução nossa.

9 "La description a toujours affaire avec un horizon d'attente préétabli, donc avec une norme, un code, un modèle préexistent. Modaliser une description, c'est interroger les degrés de complétude et de légitimité du modèle, de la taxonomie (de mots, de choses) élaborée dans un autre espace de savoir (l'encyclopédie, le dictionnaire, les sciences et techniques), c'est interroger la compétence du savoir en général". Tradução nossa.

10 "Proust ne s'intéresse [...] qu'aux seuls tableaux qui s'intègrent dans son esthétique, qui sont susceptibles de transformer notre vision de la réalité." Tradução nossa.

11 "Parce qu'il fournit au héros d'abord, mais principalement au narrateur, des objets qui serviront d'éléments conducteurs à la mémoire". Tradução nossa.

12 "Lo spazio dell'operazione classificatoria sarà quello che intercorre fra un puro dato di materia del contenuto, qualcosa come un minimo comun denominatore semantico, e la serie dei testi ai quali appunto esso è comune. Raffiguriamoci l'astratta materia come un punto quasi immateriale, in alto; in basso, la letteratura concreta come una linea retta fatta di tanti segmenti, ognuno dei quali corrisponde al sintagma lineare di un testo. In mezzo, lo spazio vacante corrisponde a una mancanza di vocaboli ben definiti per le nostre costanti - meglio definiti di quelli impiegati finora -, se la classificazione non è altro che ricerca di parole giuste per approssimazione". Tradução nossa.

Artigo recebido em janeiro de 2018. Aprovado em abril de 2018. 